\title{
A Qualitative Research on The Changing Perceptions of Luxury Consumption in The Construction of Self
}

\author{
Sonyel Oflazoğlu \\ Deptartment of Business, Mustafa Kemal University \\ PO Box 31060, Hatay, Tayfur Sökmen Campus, Turkey \\ Tel: 90-326-221-3320 E-mail: oflazoglu@mku.edu.tr
}

Received: January 26, 2017 Accepted: February 8, $2017 \quad$ Published: December 5, 2017

doi:10.5296/bms.v8i2.10651ＵRL: https://doi.org/10.5296/bms.v8i2.10651

\begin{abstract}
This work studies how the luxury experiences and perceptions of consumers are. The purpose of the study is to evaluate the modern luxury consumption experiences from a wider perspective rather than focusing on the traditional luxury consumption as a signifier of social status. The study adopts an interpretative and exploratory approach to explain in detail the contribution of the luxury consumption of consumers to the construction of self. Among the qualitative research methods, the method of keeping a diary, which sincerely transmits the processes, relations and perceptions in the daily world of the consumers was applied to the study [1]. The consumer diaries enable a ground to understand the complex structure of luxury experiences as a loop of luxury which is an indispensable part of the daily life of consumers. To achieve maximum diversity 16 participants from different age, occupation and education fields are selected. The consumer diaries are analyzed by using the inductive categorization process [2] and constant comparative method [3]. The research results are classified the luxury experiences under three categories indispensably related with processes and conditions of the self. The findings of the work are related with the present theories on self yet they pose a transition from vanity consumption, to which the perception of luxury bases, to temporary and abstract concept of consumption.
\end{abstract}

Keywords: Self Construction, conspicuous consumption, luxury experiences, consumer behavior

"Shower upon him every earthly blessing, drown him in a sea of happiness, so that nothing but bubbles of bliss can be seen on the surface; give him economic prosperity, such that he should have nothing else to do but sleep, eat cakes and busy himself with the 
continuation of his species, and even then out of sheer ingratitude, sheer spite, man would play you some nasty trick...."

\section{Dostoyevsky/Notes from the Underground}

\section{Introduction}

There is an inseparable connection in the literature on consumers' behavior between luxury, luxury objects and the meanings ascribed to luxury objects, and vanity consumption. Veblen's works [4] on traditional luxury consumption (1902) mostly focuses on social attachment and social comparison with an emphasis on the social identity needs of consumers. The characteristic features of the luxury products and brands which are produced for the meaning of social distinction are high prices, high quality, rareness and lack of need. However, recently some researchers started to define luxury from a rather more abstract and individualized dimension which remains outside of this mainstream definition. This study focuses on the moments experienced by the consumers and the meanings they ascribe to objects. It is defended here that the luxury not experienced in spaces and contexts of luxury is integrated to the daily lives of consumers while emphasizing that such luxury experiences form an inseparable whole with the self. In the frame of the findings obtained from diaries this work interprets that every object to which consumers ascribe a meaning related with luxury can be perceived as luxury and luxury experience.

Even though some researchers express luxury consumption as refined, aesthetical and glamorous life style [5] Dubois \& Czellar, a consensus between researchers on luxury's being a psychological output as a feeling and sentiment is also seen [6]. Luxury consumption defined by the feelings it arouses take an abstract form when goods are attempted to be defined as luxurious. When considered from a psychological aspect, the abstractness of the cognitive representation of the concept of luxury appears. The analysis of the words used to define luxury products in commercials reveals that the verbs and adjectives used are related with the perception of products as luxurious. The more the abstract definition of products take place in the commercials, the more the products are perceived as luxurious. In this frame the disadvantage of abstractness is the increase in the psychological distance between the consumer and the luxury product. [7] For a product to be luxurious, it is thought that it should be of quality, expensive or historic. Seldom can these features be accompanied by uniqueness or rareness, validity in any period and arbitrariness [8].

Some researchers brought a classification according to "New Luxury Products”, "Old Luxury Products" and "General Luxury Products" claiming that luxury products has reached larger masses in time and relatedly the perception of luxury has been transformed [9]. The researches on luxury consumption are as varied as the categories of luxury consumption. Researches on luxury consumption can be analyzed under three groups called "The Product and Brand Perspective”, “The Consumer Features Perspective” and "Purchase Motivation Perspective” [10]. Even though some researchers mention an all accessible luxury according to some other researchers the accessibility of luxury product by everyone result to the loss of 
the feature of being luxurious. The dominant understanding it that for a product to be luxurious it also has to be rare. Since the increase in production leads to an increase in the accessibility of the product, the image of being luxurious gets tarnished. [10],[11]. Relatedly, new strategies were developed by the producers of luxury products to reach bigger markets and increase the sales. The first among these strategies is composed of sub-brands. In this context the producers of luxury products do not use exactly their brand name but create a brand related with the brand name whose price enables the larger masses to access to the product. Consumers who cannot achieve the luxury in the top product are directed to the lower products produced by the top product producer. In another strategy the luxury brand goes beyond its portfolio and creates different products [12]. Since such approaches are motivated by the idea of presenting an opportunity of prestigious life to masses whose income level increases, the term Masstige is created by uniting the words of "Mass" and "Prestige". This concept includes the idea that luxury products can be presented to any budget and any income group. Luxury is not monopolized by kings and nobles anymore. [13].

The researchers of consumer behaviors accept spirituality as a very important factor in motivating consumption [14],[15],[16]. Even though they take the "life force" into consideration as a highly motivating action for human behavior still, its impact on the consumer choices has not yet been revealed. Works on Spiritual Motivations Consumption (SMC) in the literature are related with consumer communities, car ownership, pet ownership or activities of non-consumption. Some of these Works focus on religion. That is why, it is highly difficult to explain and conceptualize Spiritual Motivations Consumption with a single experience or behavior.

\section{The Relation between Consumption and Identity}

In terms of the marketing literature, the relation between consumption and identity continues to be an especially important field. Recently, the post-modern consumer culture has been integrated with products and consumption used because of their symbolic features. Consumers do not only buy products because of their features of advantage but also because of their symbolic features and for this reason the symbolic force should not be neglected in consumption. In this context, the consumed products and/or processes of consumption of people and symbolic consumption should be evaluated in relation with each other. The studies in the literature on the relation between the identity and the patterns of consumption have their roots in two different perspectives: One of these studies depend on the assumption that the consumption activities of people are related with their identity [17], the other assumption stresses a process of construction which cannot be fixed and has a personal dimension [17]. The classification of the features of luxury consumers are analyzed differently in researches. In a classification, the luxury consumption consumers are classified under four groups as income, culture, age and sense of self. [10] No matter what type of classification has been done, it is thought that there is an emotional bond between the owners and their luxury products [19]. In Belk's terms, luxury products has been transformed to 
meaningful objects and gained a feature recalling memories for their owners. That is why consumers, for extending, opening and strengthening their self, use the objects they ascribe importance to [20]. The specifically beloved ones among the favorite objects are reflected as the sub-set of the elements composing the identity of the luxury consumer. Due to the differences between the desired status and the actual status of people, personality crashes may occur. In this frame, buying luxury products can be useful for the resolution of the personality crashes since they can take people to the desired status [21].

That the post-modern consumers of today's world develop personal relations with brands led to the intertwined relation between brands and consumption. Therefore the symbolic meanings of possession is not used only for the membership of social groups and its communication with identity but for social status, social position and at the same time for the perception of the identity of the others. Through brands and possessions, consumers pay an effort to define themselves and differentiate themselves from other groups. As a result consumption is guided by the consumers who want to express themselves in their relation to others. In our day, the role of consumption in structuring of self is getting gradually increased [22]. Post-modern society is a society of spectacle and consumers attempt to express themselves in this spectacle and to be a part of it. When defining the consumer of our day, it is possible to discuss individuals constructing their own meanings. Consumption is a discourse on the very society of our day or the society's way of speaking with itself. Yet, the perplexing structure of the societal relations make it increasingly difficult to be a part of the society of spectacle and attempting to create a narration. [23] Accordingly, the post-modern consumer is not evaluated in the present society only as a consumer but as a product of personal consumption choices and the consumption patterns. [24]. Therefore individuals choose "life-styles and identities but not products and brands" [25]. Today's post-modern culture is settled through consumption.

\subsection{Construction of Self through Consumption}

Possession and patterns of consumption constitute and important part of the determination of people's self [20].By this way, consumption can be taken as a means of being noticed by group members and isolation from unwanted groups [26]. Consumers, by affirming meanings to the products they possess, accept them as a part of their self [20]. Within this scope they can transfer the products and brands they choose to their selves by ascribing them a special meaning. The researchers on the subject conclude that the performed consumption activities support individuals to communicate with their selves and construction of self [27]. Escalas and Bettman [28] claim that consumers use products and brands to create and image of the self and present this image to others by creating a bond between self and brand [29] express that through the products they possess, individuals can develop social identity as well. Fournier [30] reveals that some individuals use brands in a classification on "who they are". In our day what is consumed is not products but meanings [31]. The symbolic representation is in line with a more real and post-modern identity. In other words, consumers do not choose brands but they choose lives [23]. It is thought that the roots of the sentiments spread by 
luxury consumption should be sought in the consumer efforts of reflecting their identity and developing their ideal self, based on the meaning and importance the luxury products have for people buying them. While in the beginning it was thought that the motivation of luxury production is conspicuous consumption, a shift in the perspective occurred related with the fact that it basically depend on self and its original aim is to treat oneself and enjoy [32]. The luxury consumer reward and treat herself/himself by the luxury products s/he buys and enjoy this. This situation can be taken as similar to the pleasure people take when they eat chocolate or ice-cream. Luxury consumption has entered into a new era and changed dimension. Presently, luxury consumption gained importance, not because of its purchase and possession but as the pleasure of living and make others live the luxury product. The researches display that the $55 \%$ of the luxury expenditures are made this way [33]. It is seen that there is a change in consumption from luxury products to luxury services. That is why there is an increase in luxury voyages during the recent ten years.

\subsection{Luxury Consumption}

Veblen's study focuses more on the social affiliation, social comparison and the needs of consumers for social identity in the traditional luxury literature. Traditionally luxury products have functional features such as high quality and high price and for categorizing the luxury products and brands as a tool of social discrimination they are equipped with elements such as rareness, uniqueness, being the one and only and aesthetics. Recent studies support the idea that the luxury products and experiences gain a more abstract dimension; experiences in an unobtrusive, spiritual, intangible dimension. Therefore, consumers can add the perception of luxury to any product or experience. Another remarkable distinction is the distinction of the luxury consumption between cultures. While Western people prefer to live the luxury service, it is seen that the Eastern people prefer to buy the luxury product [34]. The reasons of luxury consumption may display changes according to the culture. In Western Culture, people consume luxury products for themselves and as they wish, yet for Eastern or developing cultures people consume luxurious products due to necessities which can be named as social pressure. This is resulted in Western cultures by the fact that people reward themselves and gain reputation through luxury consumption while in Eastern cultures other reasons occur such as supporting the society and gaining reputation through giving luxury presents [35]. The consumers have been separated to various groups as well in terms of purchase motivation. Author's, when making this separation, generally accept the idea developed by Veblen during the $19^{\text {th }}$. Century on the people's imitation of the upper income classes [4]. In this perspective, the motivation of consumption depends on vanity, hedonism and self-narration. Using luxury brands is a symbolic indication displaying that people define their social condition [36]. That is why, in our day, the science of psychology thinks that the concept of individuality is highly important for the creation of the human motivation, cognition, excitement and social identity [37]. The sense of privilege given by luxury brands brings together at the same time a distanced relation between the consumer and the luxury brand. While non-luxury consumer products are after the consumer, in case of the luxury products, the consumer runs after those brands to achieve this privilege. The dominant part, in this relation, is the luxury brand. That 
is why, the luxury brand is the decision maker for the products, for prices in particular and the consumer only accepts this fact. This situation is contradictory to the consumer oriented marketing perspective. While the luxury product consumers feel privileged, they prefer at the same time social differentiation and exclusion, because a large part of the society cannot purchase the luxury they buy [38].

The feeling of being respectable and privilege gained by the consumer through the luxury products is thought to be a result of its benefits. In cross-cultural researches it is seen that the value perception of luxury products are shaped through four dimensions as social (the value of vanity and prestige), personal (the value of materialism, hedonism and self-identity), functional (the value of quality, uniqueness, usability, reliability, durability) and financial (the value of money) [39]. The same model has been tested on various cultures in ten countries by fifteen researchers and a similarity is seen between the value perceptions of luxury consumers. [40].Consumers' process of decision to buy luxury products can be explained over five main factors: Personal perceptions in terms of the extended self, perceive hedonism, perceived vanity, perceive uniqueness and perceived quality [6]. On the other hand the perception and consciousness of ethics of the luxury consumers shows a difference as well. It is seen that the luxury consumers do not consider whether the luxury product is produced under ethical conditions. For the luxury consumers, quality, product satisfaction, dignity and self-identity seem to be more important. The main reason under such ideas of luxury consumers is that the expensive and respectable products would be free of problems in terms of ethics. According to the luxury consumers it is unthinkable that a company, a symbol of prestige producing luxury products, which demands a high price and offering quality products employ children workers and have bad working conditions for workers [41].

The changing feature of the luxury concept according to the consumer brings together a problem in the definition of who the luxury consumers are. In the researches on the subject generally the features of consumers such as their motives of purchase, behavior, values and demography have been analyzed. As a result, it is questionable whether the people and groups examined in terms of luxury consumption are in fact luxury consumers or which consumption group they represent. In an analysis of the researches on the luxury consumption it was examined who the luxury consumers are and how they can be classified, what their features are [42]. The participants of the luxury consumption researchers have been analyzed according to their distance to the luxury consumption (in terms of not doing luxury consumption), the degrees in the scale of luxury consumption (whether they consumed luxury in a given time scale), their degrees in the interest for the luxury consumption scale (the rating of the cognitive, sensual and associative expressions). According to the result, while the participants were divided into two in terms of those "informed" and "uninformed" in terms of the luxury products, the group of "informed about luxury" was divided under four groups "generally informed”, "Especially informed about luxury brands and products”, "Truly informed" and "Distrustfully informed". As stated in the previous section, the increase in the wealthy people and prosperity in the society in time, resulted with the generation of the "populent" segment which is created by the union of popular and opulent in English and 
which can be defined as popular wealthiness. The populent group have increased the demand in luxury products. The luxury producers were gladly responded to this demand and extended the scale of luxury products. That is why the luxury products do not only address a small community but masses. The reasons why the populent group buy luxury products is the superiority of the luxury products in comparison with other products, their being elegant and respectable, the relative difficulty of their being obtained, social signaling, self-indulgence, discovery and humble consumption [43]. From another aspect, it is observed that the luxury consumer does not choose luxury products only for vanity but mainly for internal motivations such as personal development, being associated with a group and belonging, self-confidence. It is seen that consumption is related directly with the individual, strengthens the self-confidence of individuals through their rewarding themselves and stimulates personal development [44].

\subsection{Luxury Experiences}

Berthon et al. [45] defines luxury as a mixture of social, individual and material. Post-modernism has changed the traditional definitions of luxury radically. Postmodern theoreticians claimed on the consumption practices that these practices are not only composed of a direct communication with others but they are purposively a completion (construction) process related with the self. [46] Tynan et al., to be able to create a ground for a different experimental perspective posed 3 customer value types derived from luxury:

$$
\begin{gathered}
\text { (symbolic/expressive) } \\
\text { (experiential/hedonic) } \\
\text { (relational) }
\end{gathered}
$$

Yet here there is a serious conceptual lack in terms of constructive perspective because here instead of the main meaning of luxury, the focal point has been determined in advance as luxury experiences. [7] According to Hansen and Wänke (2011); consumers tend to become distanced to the luxury experiences in their daily life, they beware of it and as a result luxury seems more distanced and abstract than the daily requirements. However it is claimed in our work that luxury is more accessible for all the consumers and its definition for the consumers should be made again. There are also other researchers reaching these results in their studies. Even though there are a few studies related to the construction of the elf through luxury products and brands, the classification of luxury and the luxury's relation with social class and desire have been widely analyzed in the literature. There are many ways to understand what consumers perceive as luxurious and what type of a contribution luxury has in the construction of the self. Eventually luxury products and brands may contain many sequences such as present, ideal, extended, multiple, transforming, self-experimental. In conclusion luxury experiences enable consumers to create a self-narrative in the groups they participate and feel themselves unique inside crowds. The purpose of our study is to re-organize the traditional luxury conceptualization once again and contribute to its definition. 


\section{Methodology}

People participated to this study as interviewees were selected from different age, educational, gender groups in order to understand the effect of luxury experiences on the self in depth and provide maximum variety. Primarily the objective of the study and the method to be used has been explained to the selected people and they were asked to record their luxury perceptions, experiences and ideas in their daily life to their diaries during the pre-determined 10 days period (between 15-25 December 2015). Among the sampling types, the purposeful sampling is employed, according to which the researcher uses his/her own judgment on the selection of participants, and the selection of the most appropriate participants is made by the researcher in line with the purpose. The interviewees were informed that the information they share in the diaries will be used in a scientific research. Each of the gathered diaries are composed of approximately 15 pages. The diaries have been analyzed through categorization and comparison, and related experience and expressions have been conveyed to the text as they are. The study has been conducted with people living in the Hatay province of Turkey. Though purposeful sampling 16 people were reached among whom 10 were women and 6 were man. 6 of the interviewees were graduated from graduate studies, 6 of them were had a bachelor's degree and 4 of them had high school diploma. As for the average age, 6 of the interviewees were from the age rage distribution of 25-35, 6 were from 35-45 and 3 of them were from 45-55. In the study, to understand the luxury moments of people diary research method was used. [47] The interviewees were asked to record in their diaries their experiences for ten days. The diaries, are documents in which daily experiences, moments, feelings and the result of those are recorded [48]. In the analysis of the diaries an inductive categorization process and a continuous comparison method were employed. The expressions of the interviewees were transferred to the text without any change and the interviewees were given code names while adding their age and gender information in the end of their expressions.

\section{Findings and Discussion}

Many findings were found in the diaries on material experiences, romantic feelings, feeling well, feeling happy, complementary and satisfactory elements for the interviewees' lives, all related to luxury. The interviewees explain the perception of luxury through abstract and concrete concepts. The luxury experiences were categorized in the study as stated below [49] :

Materialistic self (Multifaceted experiences of possession),

Liberating experiences, doing (liberating, oscillating, integrating and relating self),

Existential self, being (harmony of selves),

Transformative self, becoming (achievement-oriented and self-transformational)goal oriented, 
Table 1. Interviewer summary information

\begin{tabular}{|l|l|l|l|l|l|}
\hline No & Code name & Gender & Age & Education & Marital status \\
\hline $\mathbf{1}$ & Seda & Woman & 48 & Graduate & Single \\
\hline $\mathbf{2}$ & Sefa & Woman & 39 & Graduate & Single \\
\hline $\mathbf{3}$ & Meltem & Woman & 40 & Bachelor's & Single \\
\hline $\mathbf{4}$ & Dilek & Woman & 49 & Bachelor's & Single \\
\hline $\mathbf{5}$ & Ahmet & Man & 41 & Bachelor's & Single \\
\hline $\mathbf{6}$ & Deniz & Woman & 30 & Bachelor's & Married \\
\hline $\mathbf{7}$ & Burak & Man & 41 & Bachelor's & Married \\
\hline $\mathbf{8}$ & Zeynep & Woman & 40 & Bachelor's & Married \\
\hline $\mathbf{9}$ & Cem & Man & 43 & Graduate & Married \\
\hline $\mathbf{1 0}$ & Murat & Man & 42 & Graduate & Single \\
\hline $\mathbf{1 1}$ & Serra & Woman & 35 & Graduate & Single \\
\hline $\mathbf{1 2}$ & Özlem & Woman & 53 & High School & Married \\
\hline $\mathbf{1 3}$ & Şule & Woman & 32 & Graduate & Single \\
\hline $\mathbf{1 4}$ & Hakan & Man & 28 & High School & Single \\
\hline $\mathbf{1 5}$ & Buse & Woman & 26 & High School & Single \\
\hline $\mathbf{1 6}$ & Ada & Man & 29 & High School & Single \\
\hline & & & & \\
\hline
\end{tabular}

\subsection{Materialistic Self}

Possessions reflect the traditional approach, luxury object and the importance of experiences. The precious luxury product and places adopted by consumers saying "mine" define and express their materialistic self. These private possessions and eventually the multi-sensual perceptual experiences related to the easiness of the consumption of expensive "little luxuries". The traditional luxury products gain value because they are actually unnecessary and superfluous, in fact we never need them and we accept that we can use them whenever we want to. Actually the consumption of these type of luxury products ideally reflect the traditional luxury consumption. It is said as "I deserve this" but this should not be mistaken with self-care or aesthetic interventions. Examples for the Luxury Experiences related to Materialistic Possessions is as follows:

«My husband and I, we planned to buy me a car but since we do not have available cash we decided to rent the car. For renting a car for minimum 5 months, they are giving a new car worth 60 thousand TRY. For this you pay 1.000 TRY per month. Instead of buying a low model and old car for 15 thousand TRY, we decided to rent a much more luxurious car facing with the rent price. Even though the money would be wasted, we decided that comfort is more important for us. The journeys to other cities that we made with my husband is among the 
most pleased moments of our lives and we did not want to spoil it with an uncomfortable car.» (Zeynep, W,40)

«After the school I bought red meat for Bücür and Tirmak (my cats) making them experience luxury made me happy» (Seda, W, 48).

«Today I learned that I have previously bought almost the same of the shoes I try to buy for a couple of days and that they were forgotten among may shoe boxes. Their brand was highly expensive. I thought after almost making a luxury payment that, as a person who has the luxury of buying a lot of shoes, I would do the same again.» (Sefa, W,39).

"Nothing that I possess or I can possess materially is from the class of luxury for me, everything that I buy or I can buy is within my borders, what I perceive as luxury is definitely not related with possession » (Dilek, $W, 49)$

" Even though I know that I cannot participate to photography camps, while surfing in the internet I bought the material that I can only use in those places, in spite of being an unnecessary expenditure and shopping for me, buying a product related to my hobby, even if I cannot use it, made me .» (Burak, M, 41).

«Even though I do not have any need for sports shoes or sports shirts, I could not stop myself from buying shows and shirt in a nice color, even though it is a small one it was a luxury for me » (Murat, M, 42).

« Even though I did not need it, I bought sunglasses from a good brand just to spoil myself, I am not sure if the model fits my face but I thought it is preferred brand and anyway it fits (Serra, $W, 35)$

«I have facial care creams that I paid a lot of Money. From now on I am broke. I bother paying that much on creams generally and I always change my mind about buying them again. Last night, when I look at my tired face I said "I should by, I have a lot of wrinkles." Then, in the morning I said "I guess I can protect my face without paying that much, I should by a cheaper cream”. I still did not made my mind. But an honest bracket: if I had enough Money (if I had no limitations) those creams would have been bought for sure. Oh, our income-expenditure condition is actually not enough for renting cars, buying creams and even buying books, but instead of saving money, spending it, even spending it buy running into debt became our life style. My limit for what I want to buy is not my income, it is my debt/paying the debt capacity. (Zeynep, W,40)

\subsection{Realized Luxury Experiences}

There are luxury experiences remaining outside of the classical possession of luxury products. These are liberating, relaxing experiences. Liberation of one's self is related to his/her doing what s/he wants to do. Liberty can display itself through satisfaction from prohibited things. Therefore is an individual's ability to choose between the ideal and present self. Some moments unexpectedly experienced can give people happiness such as precious gifts. 
Indecision does not always stem from a choice or external forces. A natural indecision can be counted as luxury experience without a voluntary effort. Our self can be related not only with itself but with others as well and we may see this relation as a part of our self. In cases when you can separate your social self from the others you can contribute to your luxury experience. For instance, you're having a part-time job may prevent you from losing time in traffic like other people.

«I had two things to do today, after dealing with them I started to wander slowly towards the city center. I try to do these kinds of wanderings I which I slow down both my mind and body as much as possible. I consider them as one of the most valuable moments stolen from my life in a hurry. I visited the bookstores and I bought 6 books both planned and decided that time. For me buying a book is the greatest source of enrichment. Book arrive home, wait in sight for a while, they are being put in the order of reading then new books are placed to the new section of the bookshelf, they are being read in order and they are put in their final place in the bookshelf. That is the reason of my doubt about creams: a lot of books instead of one sun block» (Zeynep, W, 40)

«Today I met a friend of mine for 2-3 hours. She could not go out because she has a child. She came after putting the child to sleep and that was a luxury for her. I also planned a small vacation for myself. Considering the conditions I am in, even though it came to me as an activity beyond my limitations, I thought this activity would be good for me » (Sefa, W,39)

«Instead of sitting and working while I go to the cargo agency to return some products I hear the explosions in the Ankara train station. I do not know whether it is because of not understanding how serious things or out of bewilderment or since I thought it will do good to me, wandering in the city by bike for hours, and when I thought tens of people died there, LIVING is luxury!» (Seda, W,48)

"Being away from home almost for 1 week and when I return back the fuss about classes and holding my cats and sleep and talking to them, cleaning their litter, wandering in the garden with Bücür at night cleanse the day's stress on me and saves me from unwieldiness » (Seda, $W, 48)$

When everyone is in a hurry I can paint at home, my working hours are flexible and saving time form my hobby comes to me as a luxury, thinking of the people working in a closed place all day, makes me feel special for I have this opportunity. (Özlem, W, 53)

I love my family but living with them is hard for me, I could pass a separate house years later and I meet them and do the things I like to do with them a couple of times a week but when I go back to my house the feeling of living my world as I want to is priceless (Serra, W, 35,)

«Even though I could not find a return ticket, I went abroad with my friends, an escapade, that was a luxury experience which challenges my limits, when I had neither material no spiritual means for that, I risked it, I only thought that this will be good for me, I imagined the moments I would live in the holiday and I went » (Ahmet, M, 41) 
«In spite of missing my children, I took a long way and go from work to home by listening music, in reality I zeroize the day.» (Cem, $M, 43)$

«I ordered today a mastic liquor that costed a lot because firstly I understood that the ne I drink out does not give the same pleasure, drinking this I feel that I am in the island that I drank it first. » (Deniz, W, 30)

\subsection{Existential Luxury Experiences}

In fact existential experiences is the embodiment of body, mind and environment together. It does not involve practices that are exactly the opposite of the realized luxury experience. There many examples and cases in life in which the body reactions change according to health condition, feeling of loneliness and environmental factors. This is in fact completely composed of existential experiences. Belk (1988) and [50] Mittal (2006) name it as core-self, the innermost self and this is actually what shows what consumers like to do. In this section there are facts such as love, lack of time or beyond time, deep sentiments and loneliness. [51] Heidegger define this with harmony, reality, joy of life. What is important in this experience is practicing luxury not for the sake of practicing it but for living it. For instance: Going to meditation not because of saying I went to yoga but because of the joy of life after doing it. Reality: having freedom is luxury. Harmony: Feeling happy for others happiness or being alone.

«After leaving work, I arrived at home at six, for 45 minutes I dealt with cooking. Since my husband would be late I ate alone. After 19:30 I sit in front of the tv as someone who ate her meal, finish her work whose tea is getting ready. It is a luxury to be in the business life and work in a work in which you can spare so much time for yourself especially for those living in a developing country like Turkey where the working conditions.» (Zeynep, W, 40)

«Intelligence! It is for me the most important of the innate features. You can be successful with your intelligence and beautiful as much as it is possible, you can develop healthy relations... And the most important of it is having a good humor and understand from other's humor. Being intelligent is being able to have a laughter » (Zeynep, W, 40)

Neighborhood ... The sharing it involves always make someone feel good... but today the feeling of being in a huge residence or in a period and foreign country where I do not know anyone is Luxurious!!! Since the feeling of not being at home Works better (Seda, W, 48)

«I thought sitting at home peacefully is a luxury because the neigbors were having a family fight. In fact my whole life belonged to me and the only person at home who can make noises whenever she wants as me. Being at peace came to me as a luxury »(Sefa,W,39)

«One of the most important things in life is desire and having yhe reason to desire, it is also free » (Hakan, $M, 28)$

«I feel that I am free, before going to work spending time with my birds, their positive impact on my day is luxury » (Ada,M,29) 


\subsubsection{Luxury Experiences Related with Self-Realization}

Self-realization is the feelings and experiences of accomplishment, achievement about life. It is a process and it is related with realizing one's self. It is the dream of an ideal and future self but it is different than desire, it is more satisfying and fulfilling. A financial sponsor, a person's own abilities and capabilities or the support of his/her family are considered as luxury. More than being a success oriented process, it is related with spiritual processes such as self-transformation and go beyond oneself. It is different than desire because it has a higher possibility of realization. For Instance: Doing a Master's or PhD. degree in a high work tempo, writing thesis and achieving it.

"We met a friend tonight with who we could not see each other or a long time. It is a relation coming from 20 years ago before university life, both my and my husband's friend. We sat and talk about both our present and past. We all achieved a lot in life (house, work, car, children...) the conservation which we made with our friend with who we shared common values in the past (honesty, sense of justice, conscience) revealed that we are still highly attached to those values. Our friend on the contrary, is distanced to those values. Being still very much attached to those values which were my reason of life 20 years ago is the biggest source of happiness for me rather than all the material gains that life brought. Can there be a more special thing than one's being so happy for herself? That is a luxury that no one can have». (Zeynep, $\mathrm{W}, 40)$

During an important interview, the feeling of "I made it... With my works I did despite everything, I managed my name to be heard in the institution I worked" is really the feeling of "I achieved something". Calling my family and a friend of mine and telling it was a feeling of success as well. It was rewarding my work/studies I done even out of the academy. (Seda,W, 48)

«I made a wrong marriage decision and after a short time I got divorced, my family was not supporting but in the end I pulled myself together and I could continue living, in spite of all the gaps the important thing was the feeling of claiming my life and I achieved it (Buse, W, 26)

«There were positions suitable for me in the business owned by my family, I worked there for a short time but it was not me achieving it and I could not reflect myself. With a radical decision I went to Istanbul, leaving everything behind and I realized myself. » (Dilek, W, 49)

«After graduating from Bachelor's, I continued in a department that I did not want but I was not happy and after fulfilling the responsibilities that everyone was expecting from me, I returned back to myself and studied only the department I wanted to study, I did it by heart and naturally I managed, I felt like myself, without being obliged to, without having the problem of work or money » (Şule, W,32)

"I had a pharmacy, my family was highly approving it but I could not get any satisfaction from work, I made a decision and started to educate myself in another field, so I had another 
golden bracelet on my arm, now for three days a week I give my time and effort to it. » (Meltem, W, 40)

\section{Conclusion and Implications}

In the literature review, it is seen that not only the luxury consumer and products but the concept of luxury consumption itself has been subjected to a change and extended through time. Since this extension is in the global standards, the tendencies of people from various cultures and countries on luxury consumption have been investigated. On the subject of luxury consumption researches have been done on many subjects starting from Veblen [4] these researches extend from the definition of luxury to the features of the luxury products, to the differences in the old and new luxury and from the features of luxury consumers to the reasons of luxury consumption. Whether it is old or new, elite or mass, the researches made on the sentiments of the consumers which they make their egos in their inner self live it during the process of luxury consumption, are limited. Within this context, to make a research looking through the perspective of psychology from a depth is really necessary.

This study aims to highlight how luxury experiences and perceptions contribute to the self of the consumers. Additionally, this study does not characterize luxury only over products and brands but makes the secret luxury moments related with the self of the consumers valuable. Belk [20], reveals that in the luxury experience different opportunities for self-occur which are represented by symbolic consumption through certain events and activities rather than the extended self and displayed the importance of going beyond the self, enhancing the self and harmony. Belk's [20], Miller's [52], Klein and Hill’s [53], works are studies explaining especially the importance of possession related with luxury and why they have a special importance for evaluating the luxury moments. Material possessions do not by themselves express luxury but when a connection is built between our life and self, these material possessions have a symbolic name. Related to the realized luxury experiences our work present important findings by showing that there are luxury moments where meanings such as liberating were derived for the accomplishment of the self.

The results of the study overlaps partially with the results of Ahuvia's (2005) [21] and Hemetsberger et.al. [49] study. In fact oscillation is an important factor emphasizing the temporary features of luxury moments. One day the luxury becomes loneliness and another day coming together becomes a luxury for us. That is why the luxury moments making our lives interesting and precious are desires and controversies for which there is no perfect accomplishment. The existential experiences are the possibility of creating an alternative self and achieving it. Skousgaard [54] and Sussan et al. [55], were directed to the spiritual motivations not related especially with consumption and our study as well is to reveal the spiritual quality of luxury experience of people that they can experience any time. Generally, this study accepts that luxury is not permanent, luxury is a natural experience making people happy, flattered, satisfied, and motivated, supporting their self-realization. It is suggested in this study that for the future research different qualitative methods such as the diary method which enables interviewees to give more intimate and explanatory information to be 
employed and these studies to be made with people from different cultures for the comparison of the findings.

\section{References}

[1] Alaszewski, A. (2006). Using Diaries for Social Research, London: Sage.

[2] Kreiner, G. E., Elaine, C. H., \& Mathew, L. S. (2006). Where is the me among the we? Identity work and the search for optimal balance. Academy of Management Journal, 49 (October), 1031-57.

[3] Charmaz, K. (2006). Constructing Grounded Theory: A Practical Guide Through Qualitative Analysis, London: Sage.

[4] Veblen, T. (1902). The Theory of the Leisure Class, New York, NY: MacMillan

[5] Dubois, B., Laurent, G., \& Czellar, S. (2001). Consumer rapport to luxury: Analyzing complex and ambivalent attitudes. Consumer Research Working Paper 736, HEC. School of Management, Jouy-en Josas, France.

[6] Vigneron, F., \& Johnson, L. W. (1999). A review and a conceptual framework of prestige-seeking consumer behavior. Academy of Marketing Science Review,1999, 1.

[7] Hansen, J., \& Wänke, M. (2011). The abstractness of luxury. Journal of Economic Psychology, 32(5), 789-796.

[8] Bernard, D., Laurent, G., \& Sandor, C. (2001). Consumer Rapport to Luxury: Analyzing Complex and Ambivalent Attitudes. Paris: HEC.

[9] Silverstein, M. J., Fiske, N., \& Butman, J. (2008). Trading Up: why consumers want new luxury goods--and how companies create them. Penguin.

[10]Ghosh, A., \& Varshney, S. (2013). Luxury Goods Consumption: A Gonceptual Framework Based on Literature Review. South Asian Journal of Management, 20(2), 146-159.

[11] Yeoman, I. (2011). The changing behaviours of luxury consumption. Journal of Revenue and Pricing Management, 10, 47-50.

[12]Albrecht, C. M., Backhaus, C., Gurzki, H., \& Woisetschläger, D. M. (2013). Drivers of brand extension success: What really matters for luxury brands. Psychology \& Marketing, 30(8), 647-659.

[13]Bellaiche, J. M., Eirinberg Kluz, M., Mei-Pochtler, A., \& Wiederin, E. (2012). Luxe redux: Raising the bar for the selling of luxuries. The Boston Consulting Group. Retrieved April 12, 2013

[14]Baumgartner, H. (2002). Toward a Personology of the Consumer. Journal of Consumer Research, 29(2), 286. 
[15]Curasi, C. F., Price, L. L., \& Arnould, E. J. (2004). How individuals' cherished possessions become families' inalienable wealth. Journal of Consumer Research, 31(3), 609.

[16]Thompson, C. J. (2004). Marketplace Mythology and Discourses of Power. Journal of Consumer Research, 31(1), 162.

[17]Shankar, A. (2000). Lost in music? Subjective personal interpretation and popular music consumption. Qualitativie Market Research: An International Journal, 3(1), 27-37.

[18]Ger, G., \& Belk, R. W. (1996). Cross-cultural differences in materialism. Journal of Economic Psychology, 17(1), 55-77.

[19] Lee, M., Ko, E., Lee, S., \& Kim, K. (2015). Understanding Luxury Disposition.Psychology \& Marketing, 32(4), 467-480.

[20]Belk, R. (1988). Possessions and the Extended Self. Journal of Consumer Research, 15 (2), 139-68.

[21]Ahuvia, A. C. (2005). Beyond the Extended Self: Loved Objects and Consumers' Identity Narratives. Journal of Consumer Research, 32(June), 171-84.

[22] Ersoy, E. (2014). Tüketim aynasında "göz" e yansıyan seyirlik ve sembolik kimlikler. Sosyoloji Konferansları, (49).

[23]Binay, A. (2010). Post-modern identities created through consumption. Global Media Journal Turkish Edition, 1(1), 17-29.

[24] Firat, A. F. (1991). The consumer in postmodernity. Advances in Consumer Research, 18, 70-76.

[25]Perez, M. E., Castaño, R., \& Quintanilla, C. (2010). Constructing identity through the consumption of counterfeit luxury goods. Qualitative Market Research: An International Journal, 13(3), 219-235.

[26]Sabah-Kıyan, Ş. (2013). Revisiting Identity and Consumption Relation: Identity Construction through the Counterfeits of Luxury Consumption. Journal of Consumer and Consumption Research, 5(1), 53-78.

[27]Saenger, C., Thomas, V. L., \& Johnson, J. W. (2013). Consumption-focused self-expression word of mouth: A new scale and its role in consumer research. Psychology \& Marketing, 30(11), 959-970.

[28]Escalas, J. E., \& Bettman, J. R. (2003). You Are What You Eat: The Influence of Reference Groups on Consumers' Connections to Brands. Journal of Consumer Psychology, 13(3), 339-48

[29]Kleine, R. E., Kleine, S. S., \& Kernan, J. B. (1993). Mundane consumption and the self: A social-identity perspective. Journal of Consumer Psychology, 2(3), 209-235. 
[30]Fournier, S. (1998). Consumers and their brands: Developing relationship theory in consumer research. Journal of Consumer Research, 24(4), 343-353.

[31] Odabaş1, Y. (1999). Consumption culture: The consumption society of consuming society.İstanbul: Sistem Yayıncılık.

[32]Sung Y., Choi, S. M., Ahn, H., \& Song, Y. A. (2015). Dimensions of luxury brand personality: scale development and validation. Psychology and Marketing, 32(1), 121-132

[33]Bellaiche, J. M., Kluz, M., Eirinberg, Antonella, M. P., \& Wiederin, E. (2012). Luxe redux: Raising the bar for the selling of luxuries. The Boston Consulting Group. Retrieved from http://www.luxesf.com/wp-content/uploads/2012/06/BCG-Luxe-Redux.pdf

[34]Park, K. S., \& Reisinger, Y. (2009). Cultural differences in shopping for luxury goods: Western, Asian, and Hispanic tourists. Journal of Travel \& Tourism Marketing, 26(8), 762-777.

[35]Wong, N. Y., \& Ahuvia, A. C. (1998). Personal taste and family face: Luxury consumption in Confucian and Western societies. Psychology and Marketing,15(5), 423-441.

[36]Degen, R. J. (2009). Opportunity for luxury brands in China. IUP Journal of Brand Management, 6(3-4), 63-74.

[37]Sedikides, C., \& Spencer, S. (2007). The self: Frontiers in social psychology.New York, NY: Psychology Press. Sedikides, C., \& Gregg, AP (2008). Self-enhancement: Food for thought. Perspectives on Psychological Science, 3(2), 102.

[38]Jiang, M., Gao, D. G., Huang, R., DeWall, C. N., \& Zhou, X. (2014). The devil wears Prada: Advertisements of luxury brands evoke feelings of social exclusion. Asian Journal of Social Psychology, 17(4), 245-254.

[39]Wiedmann, K. P., Hennigs, N., \& Siebels, A. (2007). Measuring consumers' luxury value perception: a cross-cultural framework. Academy of Marketing Science Review,7(7), 333-361.

[40]Hennigs, N., Wiedmann, K. P., Klarmann, C., Strehlau, S., Godey, B., Pederzoli, D., ... \& Taro, K. (2012). What is the Value of Luxury? A Cross-Cultural Consumer Perspective. Psychology \& Marketing, 29(12), 1018-1034.

[41]Davies, A, Iain, Lee, Zoe ve Ahonkhai Ine (2012). "Do Consumers Care About Ethical-Luxury?” J Bus Ethics, 106, 37-51.

[42]Heine, K. (2010). Identification and motivation of participants for luxury consumer surveys through viral participant acquisition. The Electronic Journal of Business Research Methods, 8(2), 132-145.

[43]Granot, E., \& Brashear T. (2008). From Luxury to Populence: Inconspicuous consumption as described by female consumers. Advances in Consumer Research, 35, 
991-995.

[44]Truong, Y., \& McColl, R. (2011). Intrinsic motivations, self-esteem, and luxury goods consumption. Journal of Retailing and Consumer Services, 18, 555-561.

[45] Berthon, J. P., Pitt, L., \& Parent, M. (2009). Aesthetics and ephemerality: Observing and preserving the luxury brand. California Management Review, 52(1), 45-66.

[46]Tynan, C., McKechnie, S., \& Chhuon, C. (2009). Co-Creating Value for Luxury Brands,” Journal of Business Research, 63(November), 1156-63.

[47]Bolger, N., Davis A., \& Rafaeli E. (2003). Diary Methods: Capturing Life as It Is Lived. Annual Review of Psychology, 54(February), 579-617.

[48] Patterson, A. (2005). Processes, relationships, settings, products and consumers: The case for qualitative diary research. Qualitative Market Research: An International Journal, 8(2), 142-56.

[49]Hemetsberger, A., von Wallpach, S., \& Bauer, M. (2012). Because I'm Worth It' Luxury and the Construction of Consumers. Selves, Advances in Consumer Research, 40.

[50]Mittal, Banwari (2006), I, Me, and Mine-How Products Become Consumers’ Extended Selves. Journal of Consumer Behaviour, 5(November/December), 550-62.

[51] Heidegger, M. (1962), Being and Time, Malden, MA: Wiley- Blackwell.

[52] Miller, D. (2009). Buying time. Time, Consumption and Everyday Life: Practice, Materiality and Culture, 157-69.

[53]Klein, J. G., \& Hill, R. P. (2008). Rethinking Macro- Level Theories of Consumption: Research Findings from Nazi Concentration Camps. Journal of Macro Marketing, 28(September), 228-42

[54]Skousgaard, H. (2006). A Taxonomy of Spiritual Motivations for Consumption,” in Advances in Consumer Research,33, Ed. Connie Pechmann and Linda Price, Duluth, MN: Association for Consumer Research, 294-96.

[55]Sussan, F., Hall, R., \& Meamber L.A. (2012). Introspecting the Spiritual Nature of a Brand Divorce. Journal of Business Research, 65(April), 520-26.

\section{Copyrights}

Copyright for this article is retained by the author(s), with first publication rights granted to the journal.

This is an open-access article distributed under the terms and conditions of the Creative Commons Attribution license (http://creativecommons.org/licenses/by/4.0/) 